\title{
TYPE 2 DIABETES MELLITUS IS ASSOCIATED WITH INCREASED ARTERIAL STIFFNESS MEASURED BY THE ECHO-TRACKING METHOD
}

\author{
Elena Marinova ${ }^{1}$, Mila Boyadzhieva ${ }^{2}$, Nadezhda Hvarchanova ${ }^{3}$, Branimir Kanazirev ${ }^{1}$ \\ ${ }^{1}$ Department of Propaedeutics of Internal Medicine, Faculty of Medicine, \\ Medical University of Varna \\ ${ }^{2}$ Clinic of Endocrinology, St. Marina University Hospital, Medical University of Varna \\ ${ }^{3}$ Department of Pharmacology, Toxicology and Pharmacotherapy, Faculty of Pharmacy, \\ Medical University of Varna
}

\begin{abstract}
INTRODUCTION: Data for arterial stiffness (AS) in type 2 diabetes mellitus (T2DM) patients is important for better management of cardiovascular complications and early therapeutic approach.

AIM: The aim of this article is to obtain data for pulse wave velocity (PWV $\beta$ ) and other AS parameters in patients with T2DM without cardiovascular atherosclerotic disease and compare them with controls.

MATERIALS AND METHODS: This cross-sectional clinical investigation involves a sample of 100 patients with T2DM without cardiovascular complications and a control group of 30 healthy subjects. In all patients one-point echo-tracking measurement of carotid artery (CA) stiffness with Aloka Prosound $\alpha 7$ machine were conducted and pulse wave velocity $(\mathrm{PWV} \beta), \beta$-stiffness index, arterial compliance (AC), augmentation index (AI), Peterson's modulus (Ep) were measured.

RESULTS AND CONCLUSION: Our results showed the mean value of PWV $\beta$ on the left CA (L) in the group of patients with T2DM is $7.37 \pm 1.32 \mathrm{~m} / \mathrm{sec}$ and on the right CA $(\mathrm{R})$ is $7.42 \pm 1.33 \mathrm{~m} / \mathrm{sec}$. The performed t-test showed statistical significance of the differences of $P W V \beta(L)$ and PWV $\beta(R)$ in the studied group, compared to the control group $(t=3.764 ; p=0.001$ and $t=3.561 ; p=0.001)$. The data showed significantly higher values of $\beta$-stiffness index $(p=0.001)$ and $E p(p=0.001)$ in patients with T2DM compared to controls. AC was significantly lower in T2DM, when it is measured on the left CA ( $p=0.001)$. AI was significantly higher in T2DM when it is measured on the right $\mathrm{CA}(\mathrm{p}=0.009)$.
\end{abstract}

Patients with T2DM are associated with significantly increased AS parameters compared to controls.

Keywords: pulse wave velocity, arterial stiffness, diabetes mellitus, echo-tracking

Address for correspondence:

Elena Marinova

Faculty of Medicine

Medical University of Varna

55 Marin Drinov St

9002 Varna

e-mail:elena.marinova@mu-varna.bg

Received: July 9, 2020

Accepted: September 18, 2020

\section{INTRODUCTION}

Arterial stiffness (AS) occurs early in the development of type 2 diabetes mellitus (T2DM) and is a marker of subclinical atherosclerosis (1). It is associated with the occurrence of structural changes in the arterial wall such as thickening, increase in vascular diameter and medial calcification. Such changes in the elastic arteries lead to functional consequenc-

Scripta Scientifica Medica, 2020;52(3):7-11 
es and an increase in the pulse wave velocity (PWV) passing through them.

AS is considered a non-traditional cardiovascular risk factor with an independent predictive value for cardiovascular events in high-risk patients, such as those with T2DM $(2,3,4)$. The applanation tonometry measuring carotid-femoral PWV (cf-PWV) is specified by the gold standard guidelines in AS measurement. Another modern methodology for measuring local AS is echo-tracking (ET) $(3,5)$. It combines the advantages of $\mathrm{B}$-mode images with radio frequency technology and high resolution $(6,7)$. The carotid artery is of particular interest both because of its anatomical location and because of the predictive value of measured carotid PWV for cardiovascular events demonstrated in studies (8). There is evidence of correlation of local carotid stiffness (PWV $\beta$ ) with cf-PWV and therefore with the risk of cardiovascular morbidity and mortality (3).

T2DM is associated with an increased risk of accelerated atherosclerosis and cardiovascular complications (9). Recent data from studies indicate PWV $\beta$ reference values in healthy individuals, but data for patients with T2DM are currently scarce (10). Accumulation of AS data in patients with T2DM would allow better management of cardiovascular complications and therapeutic intervention in the subclinical atherosclerosis phase.

\section{AIM}

The aim of this article is to obtain data for $P W V \beta$ and other AS parameters in patients with T2DM without cardiovascular atherosclerotic disease and compare them with controls.

\section{MATERIALS AND METHODS}

This cross-sectional clinical investigation involved a sample of 48 adult males and 52 females with T2DM without cardiovascular complications. In the control group, 30 healthy individuals were enrolled. This study was conducted between October 2018 and November 2019 at St. Marina University Hospital, Varna. Patients with type 1 diabetes mellitus (T1DM), uncontrolled hypertension and absolute atrial fibrillation arrhythmia were excluded.

The results of 100 patients with T2DM subjected to one-point echo-tracking measurement of the two common carotid arteries with an Aloka Prosound a7 device equipped with a high-frequency transducer were summarized. The measurement was performed at $2 \mathrm{~cm}$ proximal to the bifurcation, in the largest diameter of the artery, with the marker placed on the adventitia. At least 6 consecutive cardiac cycles were recorded. The time was in the morning in a fasting state, after 15 minutes of bed rest, in the supine position. Immediately before the ultrasound examination, brachial arterial pressure and central systolic aortic pressure (CASP) were measured using a device Caspal A-pulse CASP-AL (HealthSTATS Int.). Parameters of AS were calculated automatically by the software and were the following: PWV $\beta, \beta$-stiffness index, AC, AI, and Ep. The additional data collected included patient demographic characteristics, medical history, anthropometry, lipid and glucose levels. The study has been approved by the local Ethical Committee of the Medical University of Varna - 78/25.10.2018.

\section{Statistical methods:}

Quantitative variables were described with mean and standard deviation. Qualitative variables were described by: number of observations and relative frequency distribution. To determine the type of distribution of the studied data, the KolmogorovSmirnov test was performed. An independent t-test was used to compare the mean values of the parameters in the two studied groups. The data were processed through a specialized statistical package for personal computer SPSS for Windows, version 25.

\section{RESULTS}

The sample included patients with T2DM aged 39-73 years (mean age 57.7, $S D \pm 7.48$ ). Mean duration of T2DM was $6.7 \pm 6.3$ years. Fifty percent were newly diagnosed. Baseline characteristics differed significantly in the study and in the control group - only in the values of waist circumference $(\mathrm{p}=0.01)$ and $\mathrm{BMI}$ $(\mathrm{p}=0.05)$ (Table 1).

Our results showed the mean value of $P W V \beta$ on the left $\mathrm{CA}(\mathrm{L})$ in the group of patients with T2DM is $7.37 \pm 1.32 \mathrm{~m} / \mathrm{sec}$ and $P W V \beta$ on the right $C A(R)$ is $7.42 \pm 1.33 \mathrm{~m} / \mathrm{sec}$. In the control group: $\mathrm{PWV} \beta$ (L) was $6.37 \pm 0.94 \mathrm{~m} / \mathrm{sec}$ and $\mathrm{PWV} \beta(\mathrm{R})$ was $6.43 \pm 1.11 \mathrm{~m} / \mathrm{sec}$. The performed t-test showed statistical significance of the differences between PWV $\beta(\mathrm{L})$ and $\mathrm{PWV} \beta(\mathrm{R})$ in the study group, compared to the control group $(\mathrm{t}=3.764 ; \mathrm{p}=0.001$ and $\mathrm{t}=3.561 ; \mathrm{p}=0.001)$. 
Elena Marinova, Mila Boyadzhieva, Nadezhda Hvarchanova et al.

Table 1. Baseline characteristics of the study and control group

\begin{tabular}{|c|c|c|c|}
\hline Parameters & $\begin{array}{c}\text { T2DM } \\
\text { mean } \pm \text { SD }\end{array}$ & $\begin{array}{c}\text { Controls } \\
\text { mean } \pm \text { SD }\end{array}$ & $\mathbf{p}$ \\
\hline Age (years) & $57.70 \pm 7.48$ & $56.76 \pm 6.98$ & 0.54 \\
\hline Duration of DM (years) & $6.75 \pm 6.37$ & & \\
\hline Height $(\mathrm{cm})$ & $166.70 \pm 10.11$ & $168.28 \pm 9.14$ & 0.47 \\
\hline Weight (kg) & $90.67 \pm 20.84$ & $84.08 \pm 20.34$ & 0.13 \\
\hline BMI $\left(\mathrm{Kg} / \mathrm{m}^{2}\right)$ & $32.41 \pm 6.61$ & $29.67 \pm 6.08$ & $0.05^{\star}$ \\
\hline Waist $(\mathrm{cm})$ & $108,69 \pm 14.92$ & $100.85 \pm 16.24$ & $0.01^{\star}$ \\
\hline Blood glucose $(\mathrm{mmol} / \mathrm{L})$ & $7.62 \pm 2.51$ & $5.68 \pm 0.67$ & $0.001^{\star}$ \\
\hline HBA1c & $9.17 \pm 2.44$ & $5.55 \pm 0.43$ & $0.001^{\star}$ \\
\hline Chol (mmol/L) & $5.18 \pm 1.32$ & $5.63 \pm 1.49$ & 0.15 \\
\hline $\mathrm{TG}(\mathrm{mmol} / \mathrm{L})$ & $2.30 \pm 1.68$ & $2.26 \pm 1.76$ & 0.81 \\
\hline $\mathrm{LDL}(\mathrm{mmol} / \mathrm{L})$ & $3.00 \pm 1.12$ & $3.30 \pm 1.12$ & 0.27 \\
\hline $\mathrm{HDL}(\mathrm{mmol} / \mathrm{L})$ & $1.18 \pm 0.39$ & $1.33 \pm 0.33$ & 0.11 \\
\hline Creatinin $(\mu \mathrm{mol} / \mathrm{L})$ & $78.9 \pm 21.14$ & $73.89 \pm 14.28$ & 0.29 \\
\hline $\operatorname{MDRD}\left(\mathrm{mL} / \mathrm{min} / 1.73 \mathrm{~m}^{2}\right)$ & $89.85 \pm 21.1$ & $85.21 \pm 14.67$ & 0.6 \\
\hline Hemoglobin (g/L) & $140.78 \pm 16.67$ & $141.45 \pm 13.13$ & 0.85 \\
\hline CAPS (mmHg) & $126.40 \pm 13.79$ & $125.76 \pm 12.62$ & 0.84 \\
\hline SBP (mmHg) & $134.01 \pm 14.63$ & $132.64 \pm 13.1$ & 0.13 \\
\hline $\mathrm{DBP}(\mathrm{mmHg})$ & $85.83 \pm 10.26$ & $87.50 \pm 9.83$ & 0.48 \\
\hline Pulse pressure (mmHg) & $48.08 \pm 11.53$ & $45.14 \pm 9.83$ & 0.39 \\
\hline Mean pressure $(\mathrm{mmHg})$ & $101.82 \pm 10.6$ & $101.97 \pm 10.28$ & 0.62 \\
\hline HR (beats/min) & $75.12 \pm 11.11$ & $73.17 \pm 10.31$ & 0.41 \\
\hline
\end{tabular}

${ }^{*}$ statistical significance

We compared PWV $\beta$ measured on left and right common CA and found no significant differences in the T2DM group ( $\mathrm{t}=0.56 ; \mathrm{p}=0.57)$ and in healthy controls $(\mathrm{t}=0.24 ;=0.8)$, respectively.
The data showed significantly higher values of $\beta$-stiffness index $(p=0.001)$ and $\operatorname{Ep}(p=0.001)$ in patients with T2DM compared to controls. Arterial compliance was significantly lower in T2DM, when it

Table 2. Comparison between ET parameters on the right CA

\begin{tabular}{|c|c|c|c|c|c|}
\hline \multirow{2}{*}{ Right CA } & \multicolumn{2}{|c|}{ T2DM } & \multicolumn{2}{|c|}{ Controls } & \multirow{2}{*}{$\mathbf{p}$} \\
\hline & Mean & Stand. Dev & Mean & Stand. Dev & \\
\hline$\beta$-stiffness index & 10.48 & 4.08 & 7.79 & 2.60 & $0.001^{*}$ \\
\hline $\mathrm{Ep}(\mathrm{kPa})$ & 151.34 & 60.25 & 112.11 & 40.19 & $0.001^{*}$ \\
\hline $\mathrm{AC}\left(\mathrm{mm}^{2} / \mathrm{kPa}\right)$ & 0.77 & 0.30 & 0.98 & 0.53 & 0.11 \\
\hline $\mathrm{AI}$ & 13.36 & 10.73 & 19.87 & 13.67 & $0.009^{*}$ \\
\hline$P W V \beta(m / s)$ & 7.42 & 1.33 & 6.43 & 1.11 & $0.001^{\star}$ \\
\hline
\end{tabular}

${ }^{*}$ statistical significance 
Type 2 Diabetes Mellitus is Associated with Increased Arterial Stiffness Measured by the Echo-Tracking Method

Table 3. Comparison between ET parameters on the left CA

\begin{tabular}{lc|c|c|c|c|}
\hline \multirow{2}{*}{ Left CA } & \multicolumn{2}{c}{ T2DM } & \multicolumn{2}{c|}{ Controls } & p \\
\hline$\beta$-stiffness index & Mean & Stand. Dev & Mean & Stand. Dev & $0.001^{*}$ \\
Ep $(\mathrm{kPa})$ & 10.32 & 3.83 & 7.51 & 2.11 & $0.001^{*}$ \\
AC $\left(\mathrm{mm}^{2} / \mathrm{kPa}\right)$ & 149.26 & 58.09 & 108.66 & 33.23 & $0.001^{*}$ \\
AI & 0.76 & 0.32 & 1.01 & 0.44 & 0.162 \\
PWV $\beta(\mathrm{m} / \mathrm{s})$ & 12.88 & 11.94 & 16.35 & 9.89 & $0.001^{*}$ \\
\hline
\end{tabular}

${ }^{*}$ statistical significance

is measured on the left CA ( $\mathrm{p}=0.001)$. Augmentation index is significantly higher in T2DM when it is measured on the right CA $(\mathrm{p}=0.009)$ (Table 2 and Table 3).

Positive correlations were found between PWV $\beta$ (R) and Ep ( $\mathrm{p}=0.001) ; \beta$-stiffness index $(\mathrm{p}=0.001)$; waist circumference $(\mathrm{p}=0.01)$; CASP $(\mathrm{p}=0.01)$; $\operatorname{SBP}(\mathrm{p}=0.001) ; \operatorname{PP}(\mathrm{p}=0.001) ; \operatorname{MAP}(\mathrm{p}=0.004)$; age $(p=0.002)$ and a negative correlation between PWV $\beta$ $(\mathrm{R})$ and $\mathrm{AC}(\mathrm{p}=0.001)$. Positive correlations $\mathrm{PWV} \beta$ (L) were found in AI $(\mathrm{p}=0.05)$; CASP $(\mathrm{p}=0.04) ; \mathrm{PP}$ $(\mathrm{p}=0.001)$ and $\mathrm{MAP}(\mathrm{p}=0.004)$.

\section{DISSCUSION}

In our study cohort, significantly elevated AS parameters in patients with T2DM were: PWV $\beta, \mathrm{Ep}$, $\beta$-stiffness index, AI (R). Using the ET methodology, the main indicator for AS is PWV $\beta$. Vriz et al. set the PWV $\beta$ threshold of $6.65 \mathrm{~m} / \mathrm{sec}$ at which an increase in cardiovascular risk is expected (3). Our results in the study group showed an average PWV $\beta$ value of $7.39 \mathrm{~m} / \mathrm{sec}$. PWV can serve as a prognostic factor for the development of future cardiovascular events, including MACE (11). In the Hoorn study, patients with T2DM had significantly higher values of cf-PWV and local PWV $\beta$ compared to healthy controls. Carotid AS indices independently correlated with CV events and overall mortality (12). Alvim et al., in a study conducted in the Brazilian population, found higher values of cf-PWV in individuals with T2DM regardless of the presence or absence of hypertension (13). In contrast to the measurement of AS by applanation tonometry, data obtained by the ET method are scarce in individuals with T2DM. The use of ET is appropriate in patients with T2DM, as it is not affected by abdominal obesity. For the first time, our study directly compared the ET parameters of the two common carotid arteries, without finding significant differences.

\section{CONCLUSION}

The patients we studied with T2DM had increased AS parameters - PWV $\beta$, Ep, $\beta$-stiffness index, AI, and decreased AC. These changes are associated with subclinical atherosclerosis. The ET technique can be useful for early detection of functional vascular changes, where therapeutic intervention would be particularly valuable.

\section{REFERENCES}

1. Palombo C, Kozakova M. Arterial stiffness, atherosclerosis and cardiovascular risk: pathophysiologic. Vascul Pharmacol. 2016;77:1-7. doi: 10.1016/j. vph.2015.11.083.

2. Laurent $S$, Cockcroft J, Van Bortel L, Boutouyrie $P$, Giannattasio C, Hayoz D, et al. European network for non-invasive investigation of large arteries. Expert consensus document on arterial stiffness: methodological issues and clinical applications. Eur Heart J. 2006; 27(21):2588-605. doi: 10.1093/ eurheartj/ehl254.

3. Vriz O, Druissi C, La Carrubba S, Di Bello V, Zito C, Carerj S, et al. Comparison of sequentially measured Aloka echo-tracking one-point pulse wave velocity with SphygmoCor carotid-femoral pulse wave velocity. SAGE Open Med. 2013; 1:2050312113507563. doi: $10.1177 / 2050312113507563$.

4. Shirwany NA, Zou MH. Arterial stiffness: a brief review. Acta Pharmacol Sin. 2010; 31(10):1267-76.

5. Avdeeva IV, Oleynikov VE, Melnikova EA. EchoTracking is a novel technology to assess structural and functional properties of carotid arteries. Sovrem Tehnol Med. 2016; 8(2):119-27. doi: 10.17691/stm2016.8.2.16. 
Elena Marinova, Mila Boyadzhieva, Nadezhda Hvarchanova et al.

6. Liabeuf $\mathrm{S}$, Bourron $\mathrm{O}$, Vemeer $\mathrm{C}$, Theuwissen E, Magdeleyns E, Aubert CE, et al. Vascular calcification in patients with type 2 diabetes: the involvement of matrix Gla protein. Cardiovasc Diabetol. 2014; 13:85. doi: 10.1186/1475-2840-13-85.

7. Magda S, Ciobanu A, Florescu M, Vinereanu D. Comparative reproducibility of the noninvasive ultrasound methods for the assessment of vascular function. Heart Vessels. 2013; 28(2):143-50. doi: 10.1007/s00380-011-0225-2.

8. Zhong Q, Hu MJ., Cui YJ, Liang L, Zhou MM, Yang YW, et al. Carotid-femoral pulse wave velocity in the prediction of cardiovascular events and mortality: an updated systematic review and meta-analysis. Angiology. 2018; 69(7): 617-29. doi:10.1177/0003319717742544.

9. Stary HC, Chandler AB, Dinsmore RE, Fuster V, Glagov S, Insull W Jr, et al. A definition of advanced types of atherosclerotic lesions and a histological classification of atherosclerosis. A report from the committee on vascular lesions of the Council on arteriosclerosis. Circulation. 1995; 92(5):1355-74. doi: 10.1161/01.cir.92.5.1355.
10. Vriz O, Aboyans V, Minisini R, Magne J, Bertin N, Pirisi M, et al. Reference values of one-point carotid stiffness parameters determined by carotid echotracking and brachial pulse pressure in a large population of healthy subjects. Hypertens Res. 2017; 40(7):685-95. doi: 10.1038/hr.2017.24..

11. Garcia-Carretero R, Vigil-Medina L, Barquero-Perez O, Ramos-Lopez J. Pulse wave velocity and machine learning to predict cardiovascular outcomes in prediabetic and diabetic populations. J Med Syst. 2019;44(1):16. doi: 10.1007/s10916-019-1479-y.

12. Van Sloten TT, Schram MT, van den Hurk K, Dekker JM, Nijpels G, Henry RM, et al. Local stiffness of the carotid and femoral artery is associated with incident cardiovascular events and all-cause mortality: The Hoorn study. J Am Coll Cardiol. 2014; 63(17):1739-47. doi: 10.1016/j.jacc.2013.12.041.

13. de Oliveira Alvim R, Santos PCJL, Musso MM, de Sá Cunha R, Krieger JE, Mill JG, et al. Impact of diabetes mellitus on arterial stiffness in a representative sample of an urban Brazilian population. Diabetol Metab Syndr. 2013;5(1):45. doi: 10.1186/1758-5996-5-45. 